\title{
An Analysis and Reflection on Reading of College Students' WeChat Reading*
}

\author{
Yuchen Zheng \\ Xiamen University Tankankee College \\ Xiamen, China 363105
}

\author{
Que'er Hong \\ Xiamen University Tankankee College \\ Xiamen, China 363105
}

\begin{abstract}
The fragmented reading of the Internet era has greatly impacted college students' reading preferences. Through WeChat, college students get text reading, image appreciation, sound communication, so WeChat is that they use mobile Internet terminal to read the new way. Through the analysis of the use about college students' WeChat, the following conclusions are drawn: from the motivation of college students' using WeChat, the demand for knowledge growth is the strongest, and the demand for emotional consumption is the weakest. From the reading content of college students' WeChat, the campus consulting category, especially the school's WeChat is the primary concern and reading of college students. Based on this study, it is found that it is necessary to guide students to use a reasonable WeChat, play the role of WeChat in the growth and emotional needs of college students. On the other hand, the universities should pay attention to the development of WeChat function and play the role of new media Media "to the cultural people" role, to serve the needs of students to grow.
\end{abstract}

Keywords-micro-letter; status analysis; value guidance

\section{INTRODUCTION}

College students born in 90s as the "original people" in the era of network media, mobile Internet has laid a deep brand mark on them. The perfect combination of special mobile devices and the Internet, so portable, smart phones even become part of their body. Through WeChat, college students get text reading, image appreciation, sound communication, so WeChat is that they use mobile Internet terminal to read the new way.

In recent years, with the development of mobile Internet, reading behavior based on WeChat has become an identity of college students, and the relationship between WeChat and college students has become a hot topic in academic circles.

The investigation and analysis of college students use WeChat subscription, we can further understand the students' electronic reading behavior, essence and value orientation, insight behind the use of motivation, to help the universities to make full use of new means of communication and innovation of Ideological and political education work, to achieve the ideological guidance and value guidance, to achieve cultural people the educational goal of education.

*Project source: Xiamen University Tankahkee college students' innovation and entrepreneurship projects in 2017 (No. 201713469081)

\section{BACKGROUND AND ISSUES RAISED}

In order to study the current situation of College Students' WeChat subscription, according to the basic principle of sampling survey, this paper adopts random sampling principle, taking proper account of school distribution and professional distribution and choose three different types, levels of colleges and universities such as Xiamen University Jiageng College, Huaqiao University and Xiamen Software Vocational and Technical Schools.

The questionnaire was conducted in December 2016 January 2017, and a total of 360 questionnaires were distributed. Among them, 343 valid questionnaires were retrieved, $95.27 \%$ were valid questionnaires. The sample as a whole has a good representation

The content of the questionnaire is mainly for the students to subscribe to the situation and the use of motivation to investigate the situation, from the Li Kete fivepoint scale, from the very recognized, more recognized, generally recognized, do not recognize, do not recognize the assignment of $5,4,3,2,1$, the greater the score, the more intense degree of perception.

Media Dependency Theory that people will form a dependency between the media. In other words, the importance of the indivi suggests dual to meet the basic needs of the media on the importance of knowledge, including knowledge and information needs, recognition and norms of the demand and the demand for entertainment will lead people to establish a dependency between the media

Therefore, according to the theory of media dependence, this study sets out four dimensions of social interaction, personal development, information acquisition and emotional experience as the dimensions of the motivation of college students' WeChat reading. These four first-level indicators are divided into 12 secondary Observation indicators, according to the strength of the identity of the selection and assignment, obtained in social interaction, personal development, information access and emotional exchange four aspects.

This study will mainly through the quantitative and qualitative combination of research methods, the sample of the basic situation of the statistical analysis and research, hoping to solve the following problems: 
- What are the differences in the motivations of college students' WeChat subscriptions in terms of knowledge, emotion and recreation?

- Do we have a scientific guide to the use of microfinance subscriptions for college students?

\section{AN ANALYSIS OF THE CURRENT SITUATION OF MiCRO-READING OF COLLEGE STUDENTS}

Through the survey statistics, this study found that college student's uses the motivation of micro-weak differences is as follows:

\section{A. The Need for Knowledge and Information Is the Most Important Motive for College Students to Subscribe to Microseconds}

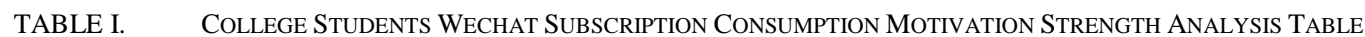

\begin{tabular}{|c|c|c|c|c|c|}
\hline motivation & do not recognize & recognized & generally & more recognize & very recognized \\
\hline 1)Get a common topic & $40(11.66 \%)$ & $58(16.91 \%)$ & $158(46.06 \%)$ & $53(15.45 \%)$ & $34(9.91 \%)$ \\
\hline $\begin{array}{l}\begin{array}{l}\text { 2)Share information to attract } \\
\text { attention }\end{array} \\
\end{array}$ & $68(19.83 \%)$ & $39(11.37 \%)$ & $147(42.86 \%)$ & $53(15.45 \%)$ & $36(10.5 \%)$ \\
\hline 3)Friends interact to keep in touch & $47(13.7 \%)$ & $85(24.78 \%)$ & $136(39.65 \%)$ & $47(13.7 \%)$ & $28(8.16 \%)$ \\
\hline 4)Expand horizons & $20(5.83 \%)$ & $33(9.62 \%)$ & $69(20.12 \%)$ & $108(31.49 \%)$ & $113(32.94 \%)$ \\
\hline 5)Rich extracurricular knowledge & $23(6.71 \%)$ & $26(7.58 \%)$ & $81(23.62 \%)$ & $101(29.45 \%)$ & $112(32.65 \%)$ \\
\hline 6)Enhance personal taste & $21(6.12 \%)$ & $31(9.04 \%)$ & $118(34.4 \%)$ & $97(28.28 \%)$ & $76(22.16 \%)$ \\
\hline 7)Learn about current events & $23(6.71 \%)$ & $35(10.02 \%)$ & $101(29.45 \%)$ & $105(30.61 \%)$ & $79(23.03 \%)$ \\
\hline 8)Tracking fashion hot spots & $28(8.16 \%)$ & $35(10.02 \%)$ & $121(32.58 \%$ & $91(26.53 \%)$ & $68(19.83 \%)$ \\
\hline $\begin{array}{l}\text { 9)Master the school's learning } \\
\text { information }\end{array}$ & $36(10.05 \%)$ & $30(8.75 \%)$ & $105(30.61 \%)$ & $102(29.74 \%)$ & $70(20.41 \%)$ \\
\hline 10)Cultivate interest & $24(7 \%)$ & $35(10.02 \%)$ & $111(32.36 \%)$ & $101(29.45 \%)$ & $72(20.99 \%)$ \\
\hline 11)Resonate & $29(8.45 \%)$ & $30(8.75 \%)$ & $122(35.57 \%)$ & $96(27.99 \%)$ & $66(19.24 \%)$ \\
\hline 12)relax & $28(8.16 \%)$ & $35(10.2 \%)$ & $106(30.09 \%)$ & $102(29.74 \%)$ & $72(20.99 \%)$ \\
\hline
\end{tabular}

As can be seen from "Table I", nearly two-thirds $(64.32 \%)$ of students expect to expand their horizons through the use and consumption of WeChat subscription, from two more agreeing and highly agreeing indicators. This is also the most important motive for college students to subscribe to the micro-subscription.

Secondly, the data in "Table I" shows that $62.12 \%$ of the students who are more agree and strongly agree that their extracurricular knowledge is enriched by the WeChat subscription. It can be seen that enriching their extracurricular knowledge through WeChat subscription is also an important motive for the college students.

\section{B. Super Half of the Students through WeChat Subscription to Meet Their Identity and Norms of Deman}

As mentioned in "Table 1", 50.44\% of the individual tastes were $50.44 \%, 50.44 \%$ of the cultivated interest, $50.15 \%$ of the learning information, $50.73 \%$ of the relieving pressure, Learn about current news $53.64 \%$.It can be seen that the subscription number of the WeChat satisfies the emotional needs of the individual in relieving the pressure and cultivating the interest, and also fulfills the demands of the students to enhance their personal taste, master the school consultation and understand the social development. The satisfaction of college students need for standardization.

\section{Through the Wechat Subscription Number to Achieve the Individual's Entertainment and Social Interaction Needs tend to Weaken the Demand}

From the results of the survey, college students through the subscription in order to achieve "get friends circle of common topics, to attract the attention of others and keep in touch with friends" and other social interaction function is not significant. To get the common topic of friend's circle, to attract the attention of others and keep in touch with friends. The three indicators as a statistical analysis of the observation points show that the proportion of those who agree (and agree with and agree very much) is only $25.36 \%$, $25.95 \% 21.86 \%$ 。 It can be seen that college students through the WeChat subscription to achieve the individual's social interaction function to a certain extent, showing a weakening trend.

\section{The Use of the Wechat Subscription in College Students Use Content Analysis}

In order to understand the content of the WeChat subscription of college students, this study mainly through the respondents to fill out the most concerned about the three micro-subscription number of the name, and then record the name of the subscription to the database. In accordance with the campus culture and information, professional academic, leisure and entertainment, life services, current affairs and other types of political categories to carry out the analysis.

First of all, from the 280 fill in the WeChat subscription of viewers, there are 143 student concerned about the school's official WeChat, accounting for $51 \%$ of the proportion of students. More than half of the students will choose the official microficient subscription. Obviously, the focus of the school's official WeChat has become a habitual choice for most students. 
Secondly, from the proportion of college students the WeChat subscription of view, the highest proportion of campus culture consulting class, reaching $41.18 \%$, accounting for nearly half of the number. Life service class at least, only $5.43 \%$.It is worth mentioning that the survey on the use of motivation for college students' WeChat subscriptions shows that students' motivation to acquire intellectual needs through microcredit is the strongest, but in reality they are concerned and read the academic class but are the least. On the one hand, there is a certain deviation between the motives and behaviors of college students, that means they have the demands for the use of knowledge subscriptions, but in reality they tend to fear the difficult and obscure of the knowledge of academic subscriptions and abandon attention to this type of micro subscription. On the other hand, the current knowledge of academic subscriptions readability, vacancy is not strong, there is a certain deviation for college students to read the taste and habits, so the lack of a certain attraction.

\section{The VAlue of THE USE OF MicRoblogGing SUBSCRIPTIONS}

\section{A. Universities Should Pay Attention to the Development of Subscription Number Function, for the Growth of Students Need to Provide Services}

From the WeChat reading function, the two basic functions of the circle of friends is the exchange of letters and the use of WeChat subscription read. With the increasing popularity of microcredit in college students, WeChat subscription as an important cultural carrier, in the guidance of college students based on the line to read the formation of effective information supply and value guidance, but also has a larger space to be excavated.

The survey results show that the school's official WeChat is the first choice for college students concerned about the subscription number, which shows that college students focus on their own interests and related development of the university. Therefore, colleges and universities should pay attention to the development of the function of microsubscription subscription number, aim at the growth point of college students 'groups, provide the learning materials and quick and convenient information materials, and attract more students' attention. In guiding students to carry out cultural reading, but also to focus on reality and virtual, online and offline combination, so that WeChat subscription to serve students to grow and become an important platform for talent.

\section{B. Colleges and Universities Should Find a Balance \\ between the WeChat Subscription Number Development, College Students and Colleges}

WeChat subscription as a profitable industry, it provides reading products with a strong business atmosphere, but in the form of unconventional, much college student's love. And the public culture products provided by colleges and universities have attached importance to content, lack of fun.

University students as the online media aborigines, they both welcome the market to provide a rich and varied, interesting and strong cultural products, and eager to get the profound cultural connotation of the cultural products.

\section{CONCLUSION}

Therefore, colleges and universities and WeChat subscription number development terminal can try to cooperate, push a new form of cultural products, colleges and universities involved in the production of cultural products, the cultural connotation of the product checks and screening, in the development of WeChat subscription number into its Rich variety of forms, increase its fun.

\section{REFERENCES}

[1] Zheng Xiao-na.Investigation and Analysis of the Status Quo of College Students' Use of Microsets - A Case Study of 208 Universities in China [J]. Journal of Ideological \& Theoretical Education (First Half Monthly Edition), 2014 (02): 83-86.

[2] Wu Yuling, Hou Yanyan. College students WeChat use and reading status analysis [J]. News front, 2016 (8): 92-94.

[3] Yu Ren, Mu Xiao, Yuan Ling. College students WeChat reading optimization and expansion [J]. Editorial Journal, 2016 (5): 33-37.

[4] Xie Xinzhou. An Empirical Study of "Media Dependence" Theory in Internet Environment $[\mathrm{J}]$. Journal of Shijiazhuang University of Economics, 2004,02: 218-224

[5] Han Yali. "90 after the" cultural life of college students and guide [J]. Education and occupation, 2015,31: 118-120. 